\title{
A PARTICIPAÇÃO FEMININA NO LEVANTE DAS ESTÁTUAS, EM ANTIOQUIA (387 D. C.)
}

\author{
Gilvan Ventura da Silva ${ }^{1}$ \\ Érica Cristhyane Morais da Silva ${ }^{2}$
}

\begin{abstract}
Resumo: O Levante das Estátuas foi um violento conflito ocorrido em 387, na cidade de Antioquia, a metrópole da província da Síria. A documentação escrita sobre o acontecimento é abundante e, por isso, somos capazes de conhecê-lo segundo diferentes perspectivas. Os principais testemunhos sobre a sedição são as XXI Homilias sobre as estátuas para o povo de Antioquia, de João Crisóstomo, e as Orações sobre o Levante das Estátuas, de Libânio. Neste artigo, pretendemos refletir sobre a presença feminina e seu significado dentro de tais narrativas, assunto que tem recebido pouca atenção dos historiadores. João Crisóstomo, por exemplo, invoca a imagem de uma suplicante ao falar em defesa de sua comunidade. Libânio também menciona mulheres agindo de tal maneira, como suplicantes. Uma referência feminina emblemática, no contexto do Levante, é a imperatriz Flacila, primeira esposa de Teodósio, cuja estátua foi alvo da fúria dos rebeldes. Com base nos testemunhos de João Crisóstomo e de Libânio pretendemos investigar o papel desempenhado pelas mulheres na revolta. Também buscaremos compreender o significado da destruição da estátua da imperatriz, uma vez que, em Roma, as imagens eram tidas como representações tangíveis dos próprios imperadores e dos membros de sua família, motivo pelo qual aqueles que contra elas atentassem poderiam se tornar réus de crime de maiestas.

Palavras-chave: Antiguidade Tardia; Antioquia; Levante das Estátuas; Mulheres; Imperatriz Flacila
\end{abstract}

\section{INTRODUÇÃO}

O Levante das Estátuas, ocorrido em Antioquia entre os meses de fevereiro e abril de 387, foi um dos mais célebres conflitos urbanos da

1 Professor Titular de História Antiga do Departamento de História e do Programa de PósGraduação em História da Universidade Federal do Espírito Santo (Ufes). Coordenador do Laboratório de Estudos sobre o Império Romano - Seção Espírito Santo (Leir/ES) e Bolsista Produtividade I-C do CNPq. No momento, executa o projeto de pesquisa intitulado Protesto, trabalho e festa na cidade pós-clássica: a ocupação da rua pela população de Antioquia (séc. IV e V d.C.).

2 Professora de História Antiga do Departamento de História e do Programa de Pós-Graduação em História da Universidade Federal do Espírito Santo (Ufes). Vice coordenadora do Laboratório de Estudos sobre o Império Romano - Seção Espírito Santo (Leir/ES). No momento, executa o projeto de pesquisa intitulado Espaços do sagrado e do Direito no mundo antigo: topografia urbana, texto e cultura material. 
Antiguidade Tardia, não apenas em virtude da sua intensidade, mas também do volume de documentos disponíveis para o seu estudo, na medida em que o Levante deu ensejo ao pronunciamento de cerca de vinte e uma homilias por João Crisóstomo, reunidas na série Homilias sobre as estátuas ao povo de Antioquia, e à elaboração das Orações sobre o Levante, de Libânio. ${ }^{3} \mathrm{O}$ conflito irrompeu no dia 25 ou 26 de fevereiro (PAVERD, 1991, p. 27), inicialmente com protestos e manifestações verbais por parte da população da cidade contra o anúncio da arrecadação de um novo imposto pelo governo imperial. ${ }^{4} \mathrm{Tal}$ mobilização popular resultou na destruição e zombaria de estátuas de bronze e painéis de madeira portando efígies do soberano, no caso, Teodósio, e de sua família (STEWART, 1999, p. 160). Em razão desses atos contra as imagens imperiais, a população teria sido acusada de crime de maiestas, como podemos deduzir das penalidades aplicadas após a supressão do Levante, das quais nos dão notícia João Crisóstomo, na época presbítero da congregação antioquena, e Libânio, um dos mais renomados professores de retórica da época tardia; bem como das leis de lesa-majestade previstas nos códigos jurídicos da época, pois sabemos que, no Império Romano tardo-antigo, episódios de destruição de imagens imperiais, em especial de estátuas, costumavam ser enquadrados como crime de maiestas. ${ }^{5}$ Em virtude da dimensão do Levante e suas particularidades - a destruição das imagens imperiais -, rumores noticiavam que a resposta de Teodósio seria a mais severa possível, razão pela qual a população aguardava, sob uma atmosfera de tensão e medo, a reação imperial, que logo se faria sentir.

Os relatos historiográficos tendem a apresentar o conflito em termos dos motivos que levaram à sua deflagração, da composição social dos seus integrantes e das ações imperial e popular diante dos acontecimentos. Ao tratar dos movimentos de resistência e revolta urbanos e rurais no século IV, Alföldy (1989, p. 226) enfatiza a heterogeneidade dos participantes do Levante das Estátuas, identificando a causa da manifestação como resultado do contexto de opressão e empobrecimento pelo qual passava o Império Romano

\footnotetext{
3 Sobre as conexốes entre retórica e história presentes nos relatos acerca do Levante das Estátuas, Quiroga Puertas tem produzido diversos trabalhos, incluindo sua tese de doutorado publicada, em 2007, com o título La retórica de Libanio y de Juan Crisóstomo en La Revolta de las Estatuas.

4 Infelizmente, não possuímos detalhes sobre a natureza do referido imposto. De acordo com Liebescheutz (1972, p. 164), na medida em que a elite fundiária de Antioquia, composta por honorati, buleutas, advogados e veteranos, tomou parte ativa no Levante, é provável que o imposto em questão constituísse uma superindictio, ou seja, uma arrecadação complementar referente à propriedade agrária.
}

5 Informações suplementares sobre o crime de maiestas no Império Romano podem ser encontradas em Lécrivain (s./d.). 
à época. Robert Browning (1952, p. 16), por sua vez, também centra a análise na diversidade social ao analisar a atuação, no Levante, de uma categoria específica da população urbana: as claques teatrais, ou seja, profissionais que, comissionados por este ou aquele ator, incentivavam a audiência a se manifestar no decorrer das performances cênicas. Assim, tanto Alföldy quanto Browning prendem-se às características sociais do Levante, considerando, na especificidade de cada estudo, as diferentes modalidades de participação popular e os motivos que levaram os habitantes de Antioquia a empreender uma ação coletiva e violenta contra o Estado imperial. Para tanto, apoiamse amiúde nos relatos de Libânio, em detrimento de João Crisóstomo. Tais estudos, voltados para os aspectos sociais do acontecimento e para uma maior exploração do depoimento de Libânio, relacionam-se à corrente teórica com base na qual se estruturam, pois filiam-se a um paradigma de interpretação fundado nos pressupostos da História Social que, de acordo com Lynn Hunt (2001, p. 2), caracteriza-se por uma modalidade de explicação histórica que direciona "seus interesses para as investigações da composição social e da vida cotidiana de operários, criados, mulheres, grupos étnicos e congêneres”, enfim, dos diversos grupos e categorias sociais. Cumpre observar, no entanto, que embora engajada na recuperação das vozes dos distintos atores sociais, em especial das personagens anônimas e subalternas, em se tratando do Levante das Estátuas essa historiografia simplesmente ignora a participação feminina, gerando assim a (falsa) impressão segundo a qual o Levante teria contado apenas com atores masculinos quando, na realidade, é possível detectar, mediante uma prospecção atenta dos testemunhos disponíveis, exemplos de atuação das mulheres no decorrer do conflito, como pretendemos demonstrar neste texto.

\section{AS MUlHeres entre o ATIVISMO POLÍtico e A SÚPliCa PIEDOSA}

Em seus relatos sobre o Levante das Estátuas, tanto João Crisóstomo como Libânio pouco elucidam quem eram os participantes efetivos da sedição. João Crisóstomo (De Statui, Hom. II, 3; Hom. II, 4; Hom. II, 10; Hom. II, 13; Hom. III, 1; Hom. III, 3; Hom. V, 3; Hom. VI, 1; Hom. XV, 1; Hom. XVII, 2), de modo um tanto ou quanto vago, refere-se aos culpados ou àqueles que deveriam ser responsabilizados pela destruição das imagens como "certos estrangeiros e aventureiros", "homens das mais diversas raças", "pecadores incontroláveis”, “blasfemos”. Já Libânio, na Oratio XIX, 28, destaca: 
Eles [os sediciosos] começaram a empregar uma linguagem ofensiva e logo as palavras se transformaram em ações que nem o mais respeitável individuo esperava que acontecesse. Quem eram essas pessoas, então? Por isso é que se pensa mais nos dançarinos de pantomima do que no sol e na lua e nas trevas!

Em outra passagem, Libânio (Or. XIX, 31) declara: "Quando os acontecimentos atingiram o ponto de se atacar as estátuas, houve alguns infratores, mas os espectadores eram muito mais numerosos do que os que cometeram esses ultrajes." Mais adiante, acrescenta o autor (Lib. Or. XIX, 33), referindo-se à quantidade de pessoas que se lançaram sobre as estátuas imperiais: "[...] rumores exageraram o número daqueles que atacaram as estátuas [...]”. Mesmo em face dessas evidências esparsas, Paverd (1991, p. 27-33) consegue extrair dos relatos de João Crisóstomo e de Libânio indícios importantes em busca de uma identificação do perfil daqueles que tomaram parte, de modo efetivo, no ultraje às imagens imperiais. As conclusóes às quais chega o autor são as seguintes: 1) ao contrário do que sugere Browning (1952, p. 13-20), não há evidência segura de que a claque teatral tenha tido uma participação relevante em todo o episódio, sendo difícil avaliar com precisão o papel desempenhado por tal categoria; 2) Libânio tenta salvaguardar a reputação de Antioquia ao atribuir os atos de violência àqueles indivíduos associados aos ludi theatralis, ao passo que João Crisóstomo busca defender a população por meio da alegação de que teriam sido "estrangeiros" os responsáveis pela destruição e zombaria das imagens. Na opinião de Paverd, ambas as atribuições de responsabilidade, a de Crisóstomo e a Libânio, não são, em absoluto, confiáveis; 3) por fim, o cenário mais provável para o autor é que, muito embora tenha havido, no Levante, a colaboração ativa de integrantes do ordo decurionis de Antioquia, é inquestionável que houve também a participação de pessoas do demos, o que nos sugere um engajamento maciço da população, ao contrário do que nos induzem a supor Libânio e João Crisóstomo, para quem o contingente de sediciosos teria sido restrito. As conclusões de Paverd, muito embora nos permitam mensurar o nível de intensidade do Levante, que teria congregado uma boa parte da população urbana, não nos informam sobre uma possível atuação feminina, o que torna o conflito um acontecimento dominado pelas figuras masculinas. As fontes, no entanto, nos revelam evidências importantes acerca do papel das mulheres no episódio.

Os conflitos que de quando em quando irrompiam nos meios urbanos do Império Romano eram amiúde qualificados pelos antigos como uma stásis ou seditio da plebs ou do pléthos, da arraia-miúda, mas não podemos perder 
de vista o fato de que os levantes urbanos foram conflitos que mobilizaram toda a cidade, ou seja, conflitos que contaram com um amplo engajamento da população e que apresentaram uma organização interna ancorada num repertório de ações violentas previstas na própria tradição romana, ${ }^{6}$ além dos aspectos simbólicos, culturais, que revestiram. Sendo as sedições eventos coletivos, a atribuição da culpa também costumava ser coletiva, como ocorreu no caso do Levante das Estátuas, fato confirmado por Libânio (Or. XXI, 5):

Em tais atos de sacrilégio e ofensa, toda a cidade compartilha alguma responsabilidade. Mesmo que apenas alguns tenham perpetrado os atos, $o$ restante não impediu que isso acontecesse e a atitude desses que permitiram fez com que fossem acusados do mesmo crime atribuído àqueles malfeitores.

A investigação e posterior julgamento tiveram por alvo não indivíduos, mas grupos de pessoas que foram responsabilizadas conforme seu grau de envolvimento no Levante:

As feridas expostas pelos incendiários e que foram causadas pelo lançamento de telhas delataram os amotinados, que foram a julgamento, e várias outras formas de identificação fizeram o mesmo com aqueles culpados pelo sacrilégio. Os cúmplices deles, aqueles que conbeciam a identidade dos culpados, e as açöes que foram perpetradas pelos seus companbeiros tornaram-se evidência e a condenação foi rápida, clara e fácil. Os prisioneiros foram classificados de acordo com a seriedade de seus crimes. Então, isto foi feito. Em seguida, os procedimentos tinham que ser instituidos imediatamente para a punição daqueles que cometeram os crimes mais graves, o que também foi realizado [...] (Lib., Or. XIX, $36-37)$.

As estratégias e procedimentos utilizados em conflitos urbanos, no Império Romano, constituem um elemento importante na definição do tipo de sedição em causa e na determinação das características do Levante

6 Para a definição desse tipo de conflito e para a compreensão do significado dos termos stásis e seditio no contexto da Antiguidade Tardia, conferir Aja Sánchez (1991, p. 359-376; 1998). A contribuição desse estudo para a definição dos levantes populares urbanos é valiosa. No entanto, nos distanciamos da perspectiva do autor em um aspecto fundamental, pois consideramos tais sedições acontecimentos não arbitrários e sistemáticos, em lugar de compreendê-los, como argumenta Aja Sánchez (1991, p. 369 e p. 373-374), como "espontâneos”, “não coordenados”, “não instrumentalizados política ou ideologicamente por nada" ou como uma "ação desorganizada, espontânea e quase intuitiva”, "uma forma de descarga emocional coletiva” em época de tensões. Sobre os levantes e protestos como um conflito político que possui uma lógica própria, consultar Zimmermann (1980, p. 195-271). Para o repertório de ações dentro dos levantes urbanos, consultar Stewart (1999, p. 164-166; 2003, p. 272-278). 
das Estátuas (SILVA, 1997, p. 157-168). Não obstante, julgamos que, na formulação dos critérios que compõem os levantes e sedições, um dado que requer a atenção do pesquisador diz respeito às relações de gênero, pois muitas das ações executadas pelos sediciosos não seriam, necessariamente, próprias apenas de homens, mas de homens e mulheres igualmente. Norman (1977, p. 289, cf. c) argumenta que o atear fogo poderia ser considerado um ato típico de categorias subalternas, que desse modo se oporiam às elites, como vemos no episódio de 354, quando a população de Antioquia, enfurecida, trucidou Teófilo, o Consularis Syriae e, em seguida, incendiou as residências da aristocracia municipal, fato mencionado por Amiano Marcelino (Res Gestae, XIV, 7) e também por Libânio (Or. I, 103). Este autor (Lib., Or. XIX, 36) ainda comenta que as "feridas exibidas pelos incendiários foram causadas pelo lançamento de telhas". As telhas que cobriam os edifícios urbanos poderiam significar apenas o que lhes é esperado ser, ou seja, partes de uma estrutura que fornecia abrigo. No entanto, esses objetos recebiam uma nova função quando utilizados como projéteis, ou seja, como armamento, nas sedições (BARRY, 1996, p. 55). Na realidade, todo e qualquer elemento móvel da cidade poderia ser mobilizado por ocasião das stáseis e seditiones, prática atestada de longa data em Roma?

As estratégias de ataque e defesa e o comportamento daqueles que, envolvidos no conflito, adotavam táticas incendiárias e recorriam ao arremesso de pedras e telhas são, sem dúvida, aspectos relevantes quando estudamos os conflitos urbanos na Antiguidade, ainda mais se levarmos em consideração a participação feminina. No estudo desenvolvido por William Barry (1996) acerca do uso das telhas como armas em tumultos, é possível perceber que esse procedimento era empregado inclusive pelas mulheres e escravos, que costumavam lançar mão de qualquer objeto ao seu alcance. Em assim sendo, num acontecimento do porte do Levante das Estátuas, nos parece altamente improvável que as mulheres não tenham tido qualquer envolvimento. Muito embora não tenhamos um relato inequívoco da atuação violenta das mulheres contra as estátuas imperiais e os edifícios públicos, não podemos, em absoluto, excluir tal possiblidade, pois sabemos que, no momento de anúncio do novo imposto, o dikasterion de Antioquia se encontrava repleto de pessoas, incluindo certamente mulheres, que teriam protestado contra o anúncio do imposto mediante gritos e zombarias, como descreve Libânio (Or. XIX, 25-29):

\footnotetext{
7 No tempo da República, segundo Plutarco (Ti. Gracc, 17), as facções em disputa não hesitaram em empregar pedras colhidas ao acaso como armas. No século IV, Amiano Marcelino (XXVI, 6, 16) também registrou o uso de telhas quebradas nos choques de rua.
} 
Lá [no dikasterion] chegou o decreto sobre o ouro, algo há muito tempo temido. O que até então parecia inacreditável era agora muito crível; a terra não poderia aguentar o fardo, e então aqueles que ouviram a ordem se lançaram ao chão, a maioria revelando sua incapacidade absoluta. [...] Eles tiveram que recorrer, portanto, ao apoio do Deus deles, invocando seu nome, para que ele pudesse persuadi-lo [o imperador] a suspender parte do fardo. O dikasterion estava lotado de pessoas - ex-governadores, buleutas, advogados, militares da reserva. [...] Quando eles [os assistentes] vieram para fora e chegaram às últimas consequências, alguns dos seus companheiros começaram a provocar desordem. Eles seguiram para o local onde provavelmente encontrariam Flaviano [o bispo da cidade], mas eles não o encontraram, então eles retornaram ao lugar onde iniciaram a revolta.

Libânio menciona, em várias passagens de suas Orações sobre o Levante das Estátuas, que as mulheres não tiveram qualquer participação nos acontecimentos perpetrados pelos amotinados, descritos como sendo apenas homens (ou jovens), membros da elite municipal e, portanto, integrantes da boulé. João Crisóstomo, por sua vez, se encarrega de confortar a população, destacando o papel do bispo, Flaviano, nas negociações com a corte imperial em favor da população da cidade, o que, sem dúvida, constituía um elemento de propaganda em favor da Igreja. Não obstante os atrativos da prédica de João Crisóstomo, bastante persuasiva por sinal, é importante salientar que a hierarquia episcopal, no século IV, ainda se esforçava por obter o controle sobre a cidade antiga, razão pela qual mesmo em Antioquia, uma das matrizes do cristianismo celebrada pelo pregador como a mais cristã das cidades, não verificamos, na época tardia, um triunfo absoluto e irreversível da fé cristã, se é que isso algum dia chegou a ocorrer. A bem da verdade, a insistência de João Crisóstomo em reforçar o papel do episcopado no Levante parece trair antes uma realidade complexa, na qual a capacidade de interferência do cristianismo na vida urbana é algo que somente existe em tese, e não na prática. Seja como for, por intermédio das homilias de João Crisóstomo constatamos que a população deveria auxiliar os seus pastores na difícil tarefa de obter a reconciliação com o poder imperial (De Statui, Hom. III, 5). É nesse contexto que as mulheres aparecem, pois, segundo o pregador, elas deveriam atuar no esforço coletivo de súplica e oração em favor da pólis, como é possível concluir da seguinte passagem:

Vamos nós numa embaixada longe daqui para a Majestade do céu! Deixenos assisti-lo [Flaviano em sua missão junto ao imperador] por meio de orações! A comunidade da Ecclesia pode fazer muito se, com uma alma 
pesarosa e com um espirito arrependido, nós oferecermos nossas preces! Não é necessário atravessarmos o oceano ou fazermos uma longa jornada. Deixe todo homem e toda mulher entre nós, quer se encontrem juntos, na Ecclesia, que permaneçam em casa, rogar a Deus com muita dedicação e

A imagem mais marcante desse modelo de participação feminina no Levante aparece, todavia, na Homilia XIII, 3, na qual João Crisóstomo descreve o comportamento de duas mulheres que decidiram interceder por um familiar que estava prestes a ser julgado pelo tribunal:

Uma visão era mais digna de pena que qualquer outra: uma mãe e uma irmã de alguém que estava entre aqueles que seriam julgados adentraram a antessala da corte de justiça, rolando sobre o pavimento e, como um espetáculo para todos, cobriam a face, mas sem mostrar qualquer tipo de vergonha. Mas isso, no contexto dessa calamidade, era permitido.

Libânio (Or. XXII, 22), por sua vez, narra uma cena similar:

Entre aqueles a ser inquiridos, havia um jovem homem que havia merecido várias honrarias em razão de algumas embaixadas e serviços cívicos que teria realizado. E havia substituido seu pai nos deveres cívicos. A mãe dele, então, descobriu a cabeça e, mostrando seus parcos cabelos envelhecidos, correu para abraçálo. Exibindo seu velho cabelo, rogou em favor de seu filho com súplicas lamentáveis. As lágrimas da mulher encharcaram os pés do juiz. Ninguém a afastou dele e nem o juiz a repeliu.

Tanto João Crisóstomo quanto Libânio descrevem situações semelhantes envolvendo mulheres. Libânio exalta a pietas da mãe que, desfazendo-se em lágrimas, foi capaz de comover até mesmo o magistrado imperial encarregado do julgamento. João Crisóstomo, por sua vez, registra a coragem de duas mulheres que, trazendo a face coberta, se lançavam ao chão com o propósito de atrair a atenção da audiência para a sua causa, numa atitude pública de humilhação. Em ambos os casos, verificamos que as mulheres se valem de mecanismos de intervenção que, embora, de certa forma, nos revelem a fragilidade da sua posição, não deixam de exibir um alto grau de ousadia, pois elas não hesitam em se introduzir num espaço cívico visando a pressionar as autoridades imperiais na tentativa de obter o perdão para os seus respectivos parentes, implicados como réus. Essa atitude é, sem dúvida, um dos traços mais marcantes da presença feminina no contexto do Levante, o que nos sugere a existência de um padrão regular de comportamento ou, melhor dizendo, uma 
estratégia de atuação das mulheres diante de uma situação de tensão extrema, como aquela vivida então pelos habitantes de Antioquia.

Em outra de suas orações, Libânio (Or. XIX, 41-44) tem o cuidado de isentar qualquer mulher de colaboração no episódio que culminou com a destruição das estátuas imperiais, recomendando que não fosse aplicado a todos, indistintamente, uma multa como punição:

Além disso, as mulheres também têm posses. Eninguém diria que alguma mulher teve qualquer participação na ofensa. Porque elas rezariam para que as portas delas fossem de ferro, tão apavoradas estão pelas suas vidas. Assim, as propriedades dessas mulheres que não têm maridos, filhos ou irmãos deveriam ficar à mercê daqueles que receberam permissão para pilhar? Se eles vierem e the dirigirem a palavra, assim: "Basileus [i.é, Teodósio], certamente, não é desejo nosso encorajar a ocorrência destes eventos. Nós não apreciamos esse tipo de conduta, nem é justo que nós sejamos reduzidos à penúria extrema, especialmente quando não há ninguém para nos aliviar dada a pobreza generalizada da cidade", qual será sua resposta a isso, basileus? Bem, e então? [...] Não, e eu não vejo qualquer possibilidade para uma multa também. Como você pode impor uma multa pecuniária para aqueles que não se provou terem feito nada errado? Além do que, se o castigo for aplicado a nós todos, você punirá aqueles a quem você diz respeitar pela devoção a Deus. E se há exceção e pessoas que não sofrerão a pena, assim alguém como eles, inocentes de culpa, reclamarão de vitimização por receberem o mesmo tratamento que os demais. Ademais, se as vitimas futuras são realmente aquelas que destruíram as estátuas, a pena que elas merecem é a morte, e não somente uma penalidade financeira.

Muito embora Libânio se esforce por livrar as mulheres de qualquer acusação, não podemos, de modo apressado, concluir que elas não tenham tido nenhuma participação no episódio, pois, na Homilia III (17), João Crisóstomo apresenta a seguinte sinopse daquilo que aconteceu no dia do Levante:

E alguns pereceram pela espada, alguns pelo fogo, outros foram entregues às feras selvagens, e não apenas homem, mas crianças. Nem a imaturidade da idade nem o tumulto do povo, pois estavam enfurecidos por demônios quando cometeram esses atos, nem o fato de o imposto ser intolerável, nem pobreza, nem que a ofensa tenha sido feita em companbia de todos, nem a promessa de que eles não teriam a audácia de repetir esses atos de novo, nem qualquer outra coisa poderia salvá-los, mas eles foram levados à cova sem demora, os soldados armados conduzindo-os e escoltando-os 
de ambos os lados, para que ninguém socorresse os condenados, enquanto as mães seguiam a distância, vendo seus filhos decapitados, mas sem se atreverem a lamentar a calamidade que recaiu sobre eles, pois o terror vence o luto e o medo suplanta a natureza! E assim como quando os homens observam, em terra, aqueles que estão naufragando, encontrandose profundamente angustiados, mas não sendo capazes de salvar aqueles que estão se afogando, o mesmo ocorreu aqui: as mães se continham por medo dos soldados.

$\mathrm{O}$ principal aspecto que ressalta da passagem acima é o caráter geral daqueles que foram presos e sumariamente executados, pois, segundo o relato de João Crisóstomo, qualquer um, fosse adulto, fosse criança era passível de receber a pena capital, não havendo razão para imaginarmos que apenas indivíduos do sexo masculino tenham sido implicados nos atos de repressão que se seguiram à dissolução do Levante. O que o autor parece sugerir é, antes, a vulnerabilidade daqueles que se encontravam reunidos em praça pública, pois qualquer um estaria ao alcance das tropas convocadas às pressas para reprimir os revoltosos. Essa conclusão é reiterada por Libânio (Or. XXII, 9), nos seguintes termos:

Por volta de meio dia, uma mudança de ideia atingiu os amotinados e culpados e inocentes sentiram um mesmo medo, pois, nesses tempos de tumulto, a punição aplicada nas cidades é universal e a ira que se sucede não distingue os líderes dos completamente inocentes.

Esse cenário de indistinção entre culpados e inocentes e de aplicação da pena de morte de modo irrestrito a todos aqueles, em tese, envolvidos no episódio, mesmo se apenas pelo fato de se encontrarem na via pública no momento de irrupção do tumulto, não é apanágio de Antioquia, pois em outras oportunidades o mesmo procedimento teria sido adotado pelas autoridades imperiais, como nos informam Eusébio de Cesareia (Vit. Const., I, 35) e João Malalas (Chron., 12, 49). Logo, é plausível argumentar que mulheres se contariam entre os revoltosos, participando efetivamente dos atos de violência e, em seguida, rogando pelos réus. Por ocasião do Levante das Estátuas, no entanto, constatamos também a existência de um outro nível no qual a figura feminina comparece, embora em circunstâncias diametralmente opostas daquelas que envolvem as mulheres do povo. Trata-se aqui da imperatriz Élia Flávia Flacila, a esposa falecida de Teodósio, cuja estátua foi alvo de depredação, assunto praticamente ignorado pela historiografia que trata do Levante de 387. 


\section{Élia Flacila, uma imperatriz sob ataque}

No que diz respeito a Élia Flacila, o lugar por ela ocupado nas narrativas de João Crisóstomo e de Libânio é restrito, mas nem por isso desprovido de significado. Em sua Oratio XX (10), Libânio nos fornece detalhes acerca da gradação de importância entre as estátuas imperiais, incluindo a da imperatriz falecida, da maneira como se segue:

Certamente, se alguém reclamasse disso [das puniçōes infligidas], esse alguém pararia de falar ao se recordar dos insultos e do tratamento dispensado àquelas estátuas. Na verdade, para tal pessoa inconveniente, o imperador poderia responder rapidamente, 'Senhor, você não ouviu aquelas palavras? Você não os viu derrubar as estátuas? Se tais ofensas tivessem sido cometidas apenas contra meu filho mais novo, eu teria que suportar. Mas se, além dele, também a mäe, e além dela, eu mesmo, e mais intolerável de tudo para mim, se eles tivessem demolido a estátua equestre de meu pai, cavalo e tudo, destruído em pedaços com todo o peso de uma cavalaria e ridicularizado os dois, como se não houvesse ninguém para se ressentir de tal maldade e não restasse ninguém para punir isto, quantos deveriam ser condenados à morte por cada uma dessas ofensas?"

Podemos inferir desse excerto a existência de uma hierarquia das representações imperiais. A ofensa mais grave seria aquela cometida contra a estátua equestre do pai do imperador, o comes Teodósio, seguidas pela do próprio imperador, da esposa e do filho mais novo. Sem dúvida, considerandose as regras de sucessão do poder no Império tardo-antigo, a estátua equestre do pai de Teodósio ocuparia uma posição proeminente, exigindo uma pronta intervenção do filho, consoante as regras da pietas que costumavam reger as relações familiares, em Roma. Em seguida, viria a estátua do próprio Teodósio e, logo após, a da sua primeira esposa, Élia Flacila, morta em 386. Tal constatação nos leva a indagar a respeito do papel desempenhado pela estátua da imperatriz na cidade de Antioquia que, além de não ser sua cidade natal, possuía um histórico de revolta contra as autoridades romanas. ${ }^{8}$

A imagem de Élia Flacila difundida por todo o Império Romano por Temístio de Bizâncio e Gregório de Nissa bem como a própria estatuária atestam a promoção, sob o governo de Teodósio, de uma autêntica devoção

8 Sobre os conflitos que opuseram imperadores e autoridades imperiais e municipais no século IV, em breve virá a público o texto 'Imperator et bouleutes' na Antiguidade Tardia: sobre os conflitos entre César Galo, Juliano, Teodósio e a elite municipal antioquena (Século IV d.C.), de Margarida M. de Carvalho e Érica C. M. da Silva (2016). 
à imperatriz, celebrada como uma Augusta "Mãe da Dinastia" e um modelo cristão de comportamento feminino. De fato, Élia Flacila era representada portando símbolos que a colocavam em posição de igualdade com Teodósio, muito embora, como argumentam Marcos (1997, p. 163-164) e Holum (1989, p. 647), tal procedimento não traduzisse qualquer concorrência com o imperador, sendo antes uma estratégia de reforço da autoridade de Teodósio. Temos ainda conhecimento de uma estátua dedicada a Élia Flacila pela população de Afrodísias, cidade na qual a imperatriz era bastante querida. Infelizmente, não dispomos mais da estátua, mas apenas da sua base, que porta a seguinte inscrição, em grego:

\begin{tabular}{|c|c|}
\hline 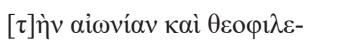 & Os habitantes de Cária ergueram \\
\hline 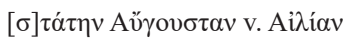 & em sua própria metrópole \\
\hline$\Phi \lambda \alpha \beta i ́ \alpha \nu$ v. $\Phi \lambda \alpha \kappa \kappa i ́ i \lambda \lambda \alpha \nu$ & uma [estátua da] eterna Augusta, \\
\hline 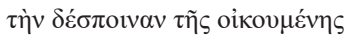 & a mais querida de Deus, \\
\hline 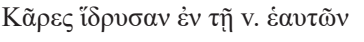 & Élia Flávia Flacila, \\
\hline vac. $\mu \eta \tau \rho о \pi о ́ \lambda \varepsilon 1 ~ v a c$. & a dona do mundo habitado \\
\hline vac. cross vac & \\
\hline
\end{tabular}

Fonte: Inscription 5.216. Honours for Aelia Flaccilla. Base de estátua, em Afrodisias. Acesso em 05 de outubro de 2015. Disponível em http://insaph.kcl.ac.uk/iaph2007/iAph050216.html

Em Antioquia, compreender o impacto da destruição da estátua de Élia Flacila no contexto de um levante urbano parecenos um propósito relevante, em especial quando se trata de uma imperatriz que nos legou um conjunto extenso de representações, consignadas em suportes numismáticos e escultóricos, além das inscrições, como a reproduzida acima (MARCOS, 1997, p. 155-164). No século XII, João Zonaras compôs um Compêndio de História no qual narra eventos ocorridos desde ao suposta criação do mundo até a morte do imperador Aleixo Comneno, em 1118. A versão de Zonaras sobre o Levante das Estátuas é dependente do relato de João Crisóstomo, embora comportando algumas diferenças. Na versão de Zonaras, a estátua em destaque é a da "primeira esposa" de Teodósio, Élia Flacila, o que suscita novas perspectivas de investigação, pois nos relatos de João Crisóstomo e de Libânio as menções à estátua da imperatriz são marginais, ao contrário do que ocorre em Zonaras, o que atesta uma mudança de tom, presente também em autores contemporâneos ao acontecimento. No século V, verificamos, nas narrativas de teor histórico, uma alteração sensível na maneira como a mulher era representada. Assim como Zonaras, Teodoreto, em sua História Eclesiástica, enfoca basicamente a estátua de Flacila, levando-nos a supor que 
os atos de destruição de imagens imperiais se circunscreveram à estátua da imperatriz, o que, em absoluto, não procede. ${ }^{9}$ A ênfase de Teodoreto e Zonaras na figura de Élia Flacila bem como a flagrante ausência de uma abordagem sobre o Levante das Estátuas nos termos das relações de gênero, conceito que ocupa, na atualidade, uma posição de destaque no debate acadêmico, tornam o tratamento da questão um desafio para os pesquisadores, convidando-nos a continuar as investigações sobre o assunto.

\section{Consideraçóes finais}

De acordo com João Crisóstomo e Libânio, testemunhas oculares dos acontecimentos de 387 , as mulheres não teriam participado efetivamente da destruição das imagens da família imperial. Todavia, nas entrelinhas da obra de ambos torna-se perceptível a participação feminina no Levante, como vemos no caso das súplicas dirigidas pelas mulheres ao Deus cristão e nas tentativas de intervenção de mães e irmãs em favor dos réus, o que as leva a ocupar o recinto de julgamento e a confrontar os próprios juízes. Atualmente, o cenário historiográfico no qual se insere o Levante das Estátuas é muito mais complexo do que há alguns anos, o que exige a adoção de novos métodos de pesquisa e de novos conceitos que permitam recuperar agentes cujas vozes estão lá, na documentação, mas que muitas vezes são ignorados pelos historiadores, comprometidos com uma visão por demais estática e unilateral dos processos históricos, como aquela que, mesmo de modo involuntário, tende a considerar os homens protagonistas dos processos históricos. Na realidade, urge não esquecermos que a cidade antiga, em especial as metrópoles, como Antioquia, abrigavam não apenas habitantes de múltiplas etnias e credos religiosos, mas também homens e mulheres que, no cotidiano, ocupavam as ruas da cidade para trabalhar, negociar, se divertir, rogar pelos seus deuses e, não raro, protestar. Nesse sentido, refletir sobre a participação feminina no Levante das Estátuas implica reconhecer as mulheres como agentes políticos importantes, assunto que carece, no Império Romano, de maior investimento

\footnotetext{
9 No Livro V, capítulo 19, de sua História Eclesiástica, escreve Teodoreto: “Em consequência das guerras contínuas, o imperador foi obrigado a impor pesados impostos às cidades do Império. A cidade de Antioquia recusou-se a aceitar o novo imposto, e quando a população viu as vítimas daquela cobrança sendo submetidas à tortura e à indignidade, iniciou açóes muito além das habituais que a multidão costuma fazer quando emerge uma oportunidade de desordem. Eles derrubaram a estátua de bronze da ilustre Flacila, como ela era chamada, e a arrastaram por quase toda a cidade. Ao ser informado desses acontecimentos, o imperador ficou indignado, como seria de se esperar. Ele privou a cidade de seus privilégios e transferiu a sua dignidade à cidade vizinha com a convicção de que assim conferiria àquela cidade a maior indignidade, pois Antioquia em tempos remotos tinha rivalidade com Laodiceia".
} 
por parte dos pesquisadores, muitas vezes iludidos por um paradigma normativo das relações sociais segundo o qual, na Antiguidade, as mulheres seriam desprovidas de capacidade política, o que nem sempre era o caso. Sem dúvida, este é um terreno fértil de trabalho para aqueles dispostos a confrontar os lugares comuns da historiografia e a reler as fontes antigas desprovidos, na medida do possível, de qualquer pré-conceito, ou seja, de qualquer formulação prévia que possa viciar o olhar que lançamos sobre o passado, tarefa sem dúvida difícil, mas ao mesmo tempo da maior relevância.

\begin{abstract}
The Riot of the Statues was one of the most documented seditions of the Fourth Century A.D. It happened in 387 A.D. at AntiochontheOrontes, the metropolis of the Syria province and an important city of the Later Roman Empire. The written sources are abundant. We are able to know about this conflict from different perspectives and multiples ancient testimonies. Traditionally, the major testimonies concerned with this sedition are the XXI Homilies on the Statues to the People of Antioch by John Chrysostom, and Orations on the Riot of the Statues by Libanius. In this paper, we aim to discuss the women presence and their representation within such narratives, a subject that has received little attention from the historians. John Chrysostom invokes the image of a female supplicant as an example of behavior in favor of her community. Libanius also mentions women acting in such manner, as supplicants. One of the most essential female presence regards the representation of the Roman empress, Flaccilla, the first wife of Theodosius I, whose statue was turned down by the rioters at Antioch along with the emperor's one. Based on the two sets of sources aforementioned, we intend to reflect on the role played by women in the sedition. We will also try to comprehend the meaning of the destruction of the empress' statue in the context of the conflict since imperial images, in the Roman Empire, were considered as the real imperial presence. Therefore, whoever responsible for their destruction could be charged with maiestas.

Keywords: Late Roman Empire. Antioch. Sedition. Women. Empress Flacila.
\end{abstract}

\title{
REFERÊNCIAS
}

\section{Fontes}

AMMIANUS MARCELINUS. Roman History. Text translated by J. Rolfe. London: Harvard University Press, 2000, v. II.

AMMIANUS MARCELINUS. The Roman History. Text translated by C. D. Yonge. London: George Bell \& Sons, 1894. b. XIV.

EUSEBIO DE CESÁREA. Vida de Constantino. Introducción, traducción y notas de Martín Gurruchaga. Madrid: Gredos, 1994.

INSCRIPTION 5.216. HONOURS FOR AELIA FLACCILLA, A white marble columnar statue base shaft ( $\mathrm{H}_{+}$approx $\mathrm{H}_{+}$1.30, diam. 0.55), broken in two, Aphrodisias. Acesso em 05 de outubro de 2015. Disponível em http://insaph.kcl. ac.uk/iaph2007/iAph050216.html 
JOHN CHRYSOSTOM. The Homilies on the Statues to People of Antioch. In: SCHAFF, P. A. (Ed.). Select Library of the Nicene and Post- Nicene Fathers of the Christian Church. Michigan: T\&T Clark, 1996, p. 315-514.v. IX.

JOHN MALALAS. The Chronicles. Text translated by E. Jeffreys; M. Jeffreys; and R. Scott. Melbourne: Australia Association for Byzantine Studies, 1986.

JOHN ZONARAS. The History of Zonaras. Text translated by T. M. Banchich and E. N. Lane. London: Routledge, 2009.

LIBANIUS. The Riots of the Statues. In: NORMAN, A. F. (Ed.). Libanius: selected works. Cambridge: Harvard University Press, 1978, v. 2.

PLUTARCH. Lives. Text translated by B. Perrin. Cambridge: Harvard University Press, 1959. v. X.

SOZOMENUS. The Ecclesiastical History* Text translated by Edward Walford. London: Henry G. Bohn, 1855.

THEODORET. History of Church. London: Henry G. Bohn, 1854.

Obras de apoio

ALFOLDY, G. A história social de Roma. Lisboa: Presença, 1989.

AJA SÁNCHEZ, J.R. 'Stáseis' e 'seditiones': uma definición del tumulto urbano en el Bajo Império. Espacio, Tiempo y Forma, série II, v. 4, 1991, p. 359-376.

AJA SÁNCHEZ, J.R. Tumultus et urbanae seditiones: sus causas - un estudio sobre los conflictos econômicos, religiosos y sociales en las ciudades tardorromanas (S. IV). Santander: Universidad de Cantabria, 1998.

BARRY, W.D. Roof tiles and urban violence in the Ancient World. Greek, Roman and Byzantines Studies, v. 37, p. 55-74, 1996.

BROWNING, R. The Riot of A.D. 387 in Antioch: the role of the theatrical claques in the Later Empire. Journal of Roman Studies, v. 42, p. 13-20, 1952.

CARVALHO, M. M.; SILVA, E. C. M. Imperator et bouleutes na Antiguidade Tardia: sobre os conflitos entre César Galo, Juliano, Teodósio e a elite municipal antioquena (século IV d.C.). 2016. No prelo.

HOLUM, K. G. Theodosian empresses. Berkeley: University of California Press, 1989.

HUNT, L. A Nova História Cultural. São Paulo: Martins Fontes, 2001.

LÉCRIVAIN, Ch. Majestas. In: DAREMBERG, C. H.; SAGLIO, E. Dictionnaire des antiquités grecques et romaines. Paris: Hachette, s/d., p. 1556-1561. T. III, 2éme partie.

LIEBESCHUETZ, J. H. W. G. Antioch: city and imperial administration in the Later Roman Empire. Oxford: Clarendon Press, 1972.

MARCOS, M. Política dinástica en la corte de Teodosio I: las imágenes de Aelia Flavia Flaccilla, in: CONGRESO INTERNACIONAL LA HISPANIA DE TEODOSIO. Segovia: IE Universidad, 1997, p. 155-164. v. I.

NORMAN, A. F. Libanius: selected works II. Cambridge: Harvard University Press, 1977.

PAVERD, F. van de. Saint John Chrysostom, The Homilies on the Statues: an introduction. Roma: Pont. Institutum Studiorum Orientalium, 1991.

QUIROGA PUERTAS, A. J. La retórica de Libanio y de Juan Crisóstomo en La Revuelta de las Estatuas. Salermo: Helios, 2007.

SILVA, G. V. da. Motivações e procedimentos dos levantes populares urbanos no IV século. Phoînix, Rio de Janeiro, v. 3, p. 157-168, 1997. 
STEWART, P. Statues in Roman societyः representation and response. Oxford: Oxford University Press, 2003.

STEWART, P. The destruction of statues in Late Antiquity. In: MILES, R. (Ed.). Constructing identities in Late Antiquity. London: Routledge, 1999, p. 159-189.

ZIMMERMANN, E. Macropesquisa comparativa sobre o protesto político. In: GURR, T. R. (Org.). Manual do conflito político. Brasília: Editora da UnB, 1985, p. 195-271. 